\title{
Functional outcome of Austin Moore Hemire Placement Arthroplasty in Fracture Neck of Femur in elderly
}

\author{
Dawadi TP 1 , Bhatta TR², Gyawali B³ ${ }^{3}$ Adhikari BR ${ }^{4}$, Giri SK ${ }^{5}$ \\ 1,2,3,4,5 National Academy of Medical Sciences, Bir Hospital, Nepal \\ Corresponding Author: Dr Tej P. Dawadi, Email: dtejprakash@yahoo.com
}

\section{Abstract}

Objective: To study the outcome of Austin Moore Hemireplacement Arthroplasty in terms of Harris Hip Score and Mobility and Aid Score in fracture neck of femur in elderly.

Design: A prospective randomized study carried out between September 2011 to August 2012 AD.

Methods: We performed 30 Austin Moore hemiarthroplasties in patients aged 65 and above that sustained a displaced femoral neck fracture and evaluated the outcome in terms of Harris Hip Score and Mobility and Aid Score.

Results: Mean HHS at 2 week was 63.93 which increased to $73.83,80.53$ and 86.48 at 6 weeks, 12 weeks and 6 months respectively with overall excellent to good result of $60 \%$. The mean MASM at 6 months was 4.0 whereas the pre-injury MASM was 4.53 .

Conclusion: Hemiarthroplasty with Austin Moore Prosthesis is safe and effective method of treatment for displaced fracture neck of femur in elderly. There was early post-operative full weight bearing mobilization with reduction in major complications. The operative duration, postoperative complications are comparable to other similar studies done elsewhere. The end functional results also depend on the associated comorbidities and optimum post op rehabilitation.

\section{Introduction}

Femoral neck fractures are one of the most common injuries in the elderly and its treatment remains one of the ongoing controversies in modern fracture care. The best treatment for fracture neck of femur is still to be determined. ${ }^{1}$ Increasing life expectancy of people has led to increase in the incidence of hip fractures and has resulted in high morbidity and mortality in 
elderly. ${ }^{2}$ Martin et al attributed this increase to gradual decline in physical activity which contributes to the bone loss. ${ }^{3}$

The factors considered in selecting treatment modalities are age of the patient, general medical condition, type of fracture, availability of facilities and socioeconomic condition of the patient. In elderly, the treatment choices are between internal fixation and prosthetic replacement. Because nonunion and osteonecrosis develop frequently after internal fixation of displaced femoral neck fractures, many surgeons recommend primary prosthetic replacement as treatment of choice. ${ }^{4}$

Prosthetic replacement allows immediate weight bearing to return to activity and helps avoid complications of recumbency and inactivity, avascular necrosis and nonunion. ${ }^{5}$

Austin Moore hemiarthroplasty is a frequently done and well accepted procedure which has good functional outcome with the low cost of the implant compared to bipolar and total hip arthroplasty. ${ }^{6}$

\section{Materials and Methods}

Type of study:

A prospective observational study

\section{Place of study:}

The department of orthopedics of Bir hospital

Duration of study: 1 year

Sample size: total of 30 patients were included in the study

Inclusion criteria:

1. Fracture of neck of femur ( Garden III and IV) with sufficient calcar

2. Age $>65$ years

\section{Exclusion criteria:}

1. Undisplaced fracture neck of femur( Garden I and II)

2. Pathological fracture

3. Multiple fractures at the same limb 


\section{Patients with open fracture}

5. Cemented hemiarthroplasty

The study was conducted after approval from the hospital ethical committee (I R B). All the cases of fracture neck of femur presented to us through the emergency and OPD were admitted and kept under traction. A detailed history and a complete physical examination were done. Patients were interviewed about their pre fracture ambulatory status and any disabilities using HHS. Radiographs were obtained and complete lab investigations. Informed consent was obtained from the patients and hemiarthroplasty with Austin Moore Prosthesis was done on elective basis through Modified Harding's direct lateral approach in supine position. ${ }^{7}$ All patients were made to sit on the $2^{\text {nd }}$ day and weight bearing as tolerated was started as soon as the patient gained muscle control. Patients were discharged usually after 5 days with cane and crutch walking training. Patients were followed up clinically and radiologically at 2 weeks, 6 weeks, 12 weeks and 6 months. Statistical data analysis was done using SPSS (statistical package for social sciences) and values of $\mathrm{P}<0.05$ were taken to indicate significance with confidence interval of $95 \%$.

\section{Results}

A total of thirty six patients were enrolled in the study, however six patients lost complete follow up and so were excluded from the study. The mean age of the patients was 74 years with SD of 5.31. Sixty percent (18) were females while $40 \%$ (12) were male. Among these, $60 \%$ were from outside the Kathmandu valley indicating that our study was done in the referral centers. Most of the cases (86.7\%) were due to low velocity injury. Involvement of right side was found to be slightly more (56.7\%) than left. Half of the patients were Garden type III and half were IV. Two third of the patients had comorbid conditions and COPD was the most common seen in $26.7 \%$ of cases. Sixty percent were having Singh's index of 3 suggesting definite osteoporosis and $36.7 \%$ were having index of 4 . Of the total $80 \%$ were community ambulator, while $16.7 \%$ were indoor ambulator and 3.3\% were active ambulator. Before injury, half of the patients were cane dependent while $30 \%$ were using cane occasionally and $20 \%$ were not using any walking aid. The mean pre-injury mobility and aid scoring matrix score was 4.53 . The mean operative delay for surgery was 11.23 days with a range from 7 to 16 days. The mean duration of hospital stay was 16.73 days. The mean duration of surgery was 52.83 minutes. The mean Harris Hip Score 
was 63.93 at 2 weeks, 73.83 at 6 weeks, 80.53 at 12 weeks and 86.48 at 6 months. The mean MASM score at 6 months was 4.02 .

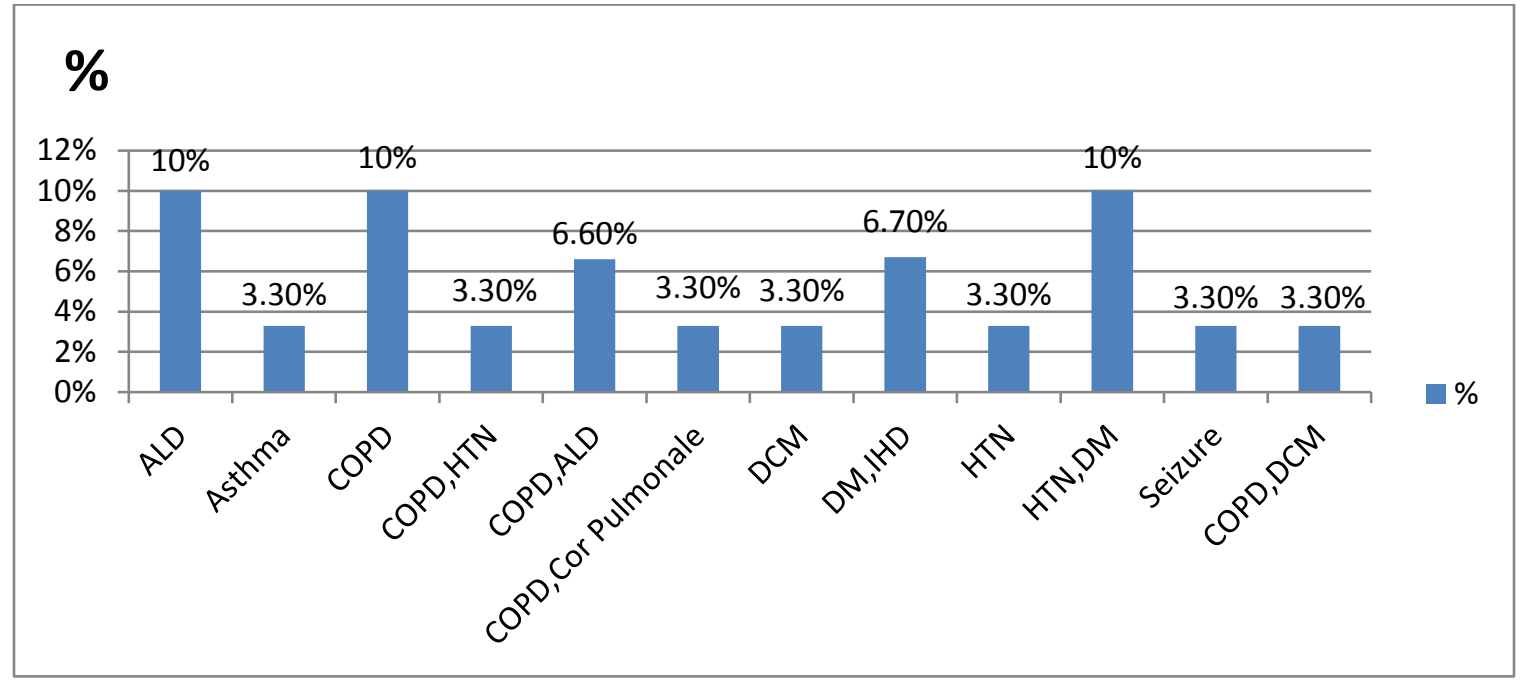

Fig : Bar diagram of co-morbid conditions of patients with fracture NOF $(n=30)$

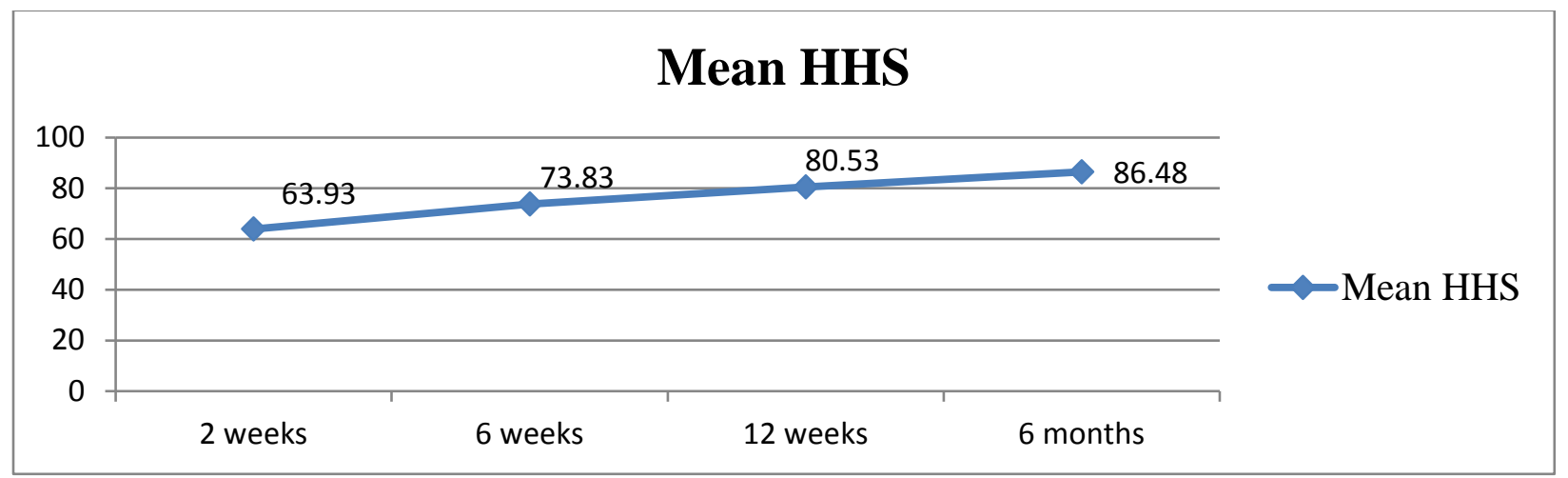

Table : Linear increase of HHS at 2,6 and 12 weeks and 6 months 


\section{Mean MASM score}

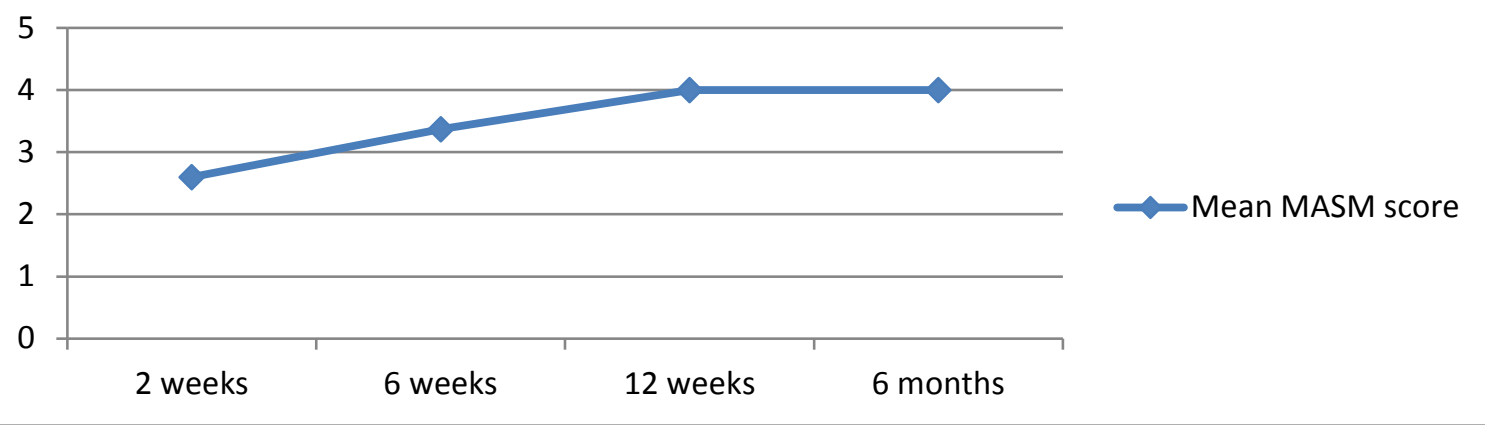

Fig : line chart of mean MASM score of patients at 2, 6 and 12 weeks and 6 months

Comparasion With Other Studies:

\begin{tabular}{|c|c|c|c|c|c|c|}
\hline Grade(HHS) & $\begin{array}{l}\text { Our } \\
\text { study }\end{array}$ & Dhar $^{8}$ & Jadhav $^{9}$ & Jensen $^{10}$ & Moore $^{11}$ & Noor $^{12}$ \\
\hline $\begin{array}{l}\text { Excellent(90- } \\
100)\end{array}$ & $13.3 \%$ & $80.2 \%$ & $65 \%$ & $30 \%$ & $31.6 \%$ & $38 \%$ \\
\hline Good(80-89) & $53.3 \%$ & & & $21.6 \%$ & $43.3 \%$ & $21 \%$ \\
\hline Fair(70-79) & $23.3 \%$ & $19.8 \%$ & $35 \%$ & $43.3 \%$ & $16.6 \%$ & $24 \%$ \\
\hline Poor $(<70)$ & $10 \%$ & & & $5 \%$ & $8.3 \%$ & $17 \%$ \\
\hline
\end{tabular}

\begin{tabular}{|l|l|l|l|l|}
\hline \multicolumn{1}{|c|}{$\begin{array}{c}\text { WALKING AID } \\
\text { DEPENDENCY }\end{array}$} & \multicolumn{2}{|c|}{ PRE-OPERATIVE } & \multicolumn{2}{|c|}{ POST OPERATIVE } \\
\hline No Aid & 6 & $20 \%$ & 2 & $6.6 \%$ \\
\hline Cane occasionally & 9 & $30 \%$ & 7 & $23.3 \%$ \\
\hline Cane dependency & 15 & $50 \%$ & 21 & $70 \%$ \\
\hline
\end{tabular}




\section{TABLE: Comparasion of Pre and Post operative dependency in walking aid}

\section{Discussion}

The patients treated were representative of the condition i e, fracture neck of femur in respect of the age and sex when compared with data from studies conducted in developed countries.

Women outnumbered men in our series with female: male ratio of $3: 2$ in keeping with the fact that femoral neck fractures are common in females due to osteoporosis similar to studies done by Dinesh Dhar et al8 and Essoh JB et al. ${ }^{13}$ The mean age of our patients was $74.06+/-5.31$ years where as that of Norrish AR et $\mathrm{al}^{14}$ was 82 years which may be due to lower life expectancy in Nepal. A total of $80 \%$ were from outside of the Kathmandu valley while $20 \%$ were from the Kathmandu valley. This speaks for the late presentation of the patients to our hospital. Majority of patients (86.7\%) sustained low velocity injury (trivial fall, fall from low height). Only $13.3 \%$ were due to high velocity (RTA). Similarly, $64 \%$ of patients were due to fall and $36 \%$ were due to RTA in the study of Essoh JB et al. ${ }^{13}$ Among the 30 cases, 50\% were Garden type III and 50\% were garden type IV. Majority of patients had comorbid conditions, with $33 \%$ having one conditions, other $33 \%$ had 2 comorbidities while rest of $33 \%$ did not have any complications. COPD was the most common co-morbid condition associated, seen in $26.7 \%$ of cases. Similarly, in the study of Dinesh Dhar et al8 comorbidity was present in $57.6 \%$ of cases.

In our study, before injury 3.3\% were active ambulators, $80 \%$ were community ambulators and $16.7 \%$ were indoor ambulators. Of the total, half were cane dependent, while $30 \%$ were using cane occasionally, $20 \%$ were not using any walking aid. Similar study done by M Clayer et al ${ }^{15}$ at the end of 3 years $46 \%$ were community ambulators, 10\% were household ambulators, $6 \%$ were nonfunctional ambulators and 29\% were non ambulators. At 10 years, only 31\% were community ambulators. This may be due to the long follow up in their case series during which the patients had decreased mobility due to age. $60 \%$ of our patients were having Singh's index of 3 which denotes definite osteoporosis, while 36.7\% were having Singh's index of 4 and only $3.3 \%$ were having index of $2 .{ }^{16}$ This shows the association of fracture with osteoporosis and the low velocity injury mechanism. The mean delay for surgery was 11.23 days with a range from 716 days. Only $10 \%$ of cases were operated within a week while rest of $90 \%$ took more than 7 
days for operation. Similarly in the study of Essoh JB et al, ${ }^{13}$ the mean delay for surgery was 17 days. The delay in surgery is due to the late presentation of the cases to the hospital. The mean duration of surgery was $52.83+/-14.03$ minutes ranging from 35 to 100 minutes in our series while it is 110 minutes in the study of Essoh JB et $\mathrm{al}^{13}$ and 57 minutes in that of parker MJ et al6 and 45 minutes in that of Dinesh Dhar et al.8

The mean HHS showed linear increase at subsequent weeks. It was 63.93+/- 8.54 at 2 weeks, which increased to $73.83+/-6.35$ at 6 weeks. Finally HHS at 12 weeks was $80.53+/-7.31$ and at 6 months were 86.48. At 2 weeks, 63.3\% had poor result but at 6 weeks $66.6 \%$ had fair result, by 12 weeks, $60 \%$ had good to excellent result and by 6 months $66.7 \%$ had good to excellent result. This is in accordance with the similar studies. The study done by Lewis et al ${ }^{17}$ had $87 \%$ good to excellent result. Study of M Clayer et $\mathrm{al}^{15}$ had HHS of 69 at 5 year follow up. Dinesh Dhar et al 8had $80.2 \%$ of good to excellent result. Similar study of JS Jensen et $\mathrm{al}^{10}$ had $52 \%$ excellent or good, $43 \%$ fair and $5 \%$ poor results.

The mean MASM score at 6 months was $4.00+/-0.87$ while the pre-injury mean MASM score was $4.53+/-1.008$ with $p$ value $>0.05$. Though the change of mean MASM score was statisticaly significant; it may be due to the short follow up.

By the final follow up at 6 months, $76.66 \%$ were community ambulators comparing to $80 \%$ before injury. $70 \%$ of patients were cane dependent comparing to $50 \%$ before injury. This shows $95 \%$ of patients regained the pre-injury ambulatory status while $20 \%$ of additional patients required additional walking aids. Essoh JB et $\mathrm{al}^{13}$ had $50 \%$ of patients walking without support at 14 months follow up and completely returned to pre-injury levels of activity while $16.6 \%$ required walking aid which is consistent with our study.

Complications were seen in $23.3 \%$ of patients. Among the total $6.6 \%$ had hip pain and similarly $6.6 \%$ had thigh pain. Limb length discrepancy of $2.5 \mathrm{~cm}$ was noted in $3.3 \%$ of cases and wound infection was found in $3.3 \%$ of cases. One case (3.3\%) was suspected of DVT at $2^{\text {nd }}$ post op day clinically, but couldn't be confirmed with Doppler due to lack of immediate facility of Doppler. This frequency of thromboembolism is similar to the meta-analysis on rate of post-operative venous thromboembolism in orthopedic surgery in Asian population done by Kanchanabat $B$, Stapanavatr $\mathrm{S}$ et $\mathrm{al}^{18}$ in which venous thromboembolism was seen in $4.5 \%$ and symptomatic pulmonary thromboembolism was seen in $0.6 \%$. However our patient improved with mobilization and stockinet and without definitive treatment for DVT. Similarly, in the study of Kuokkanen $\mathrm{H}$, 
Lehtonen J, Korkala $\mathrm{O}^{19}$, complications were seen in $13.5 \%$ of cases. JS Jensen et $\mathrm{al}^{10}$ in their case series had complications in $39.6 \%$. Hip pain was found to be significantly associated with inadequate calcar seating in the study done by Sharif Km, Parker MJ. Norrish AR, Rao J, Parker $\mathrm{MJ}^{20}$ showed constant hip pain in $6 \%$ which is consistent to our finding of $6.6 \%$. In the study of D M Smith ${ }^{21}$ wound complications were significantly associated with diabetes, obesity and long procedures. In our study, we had wound infection (superficial) in 3.3\%. P Weinrauh ${ }^{22}$ in his study had intraoperative fractures in $14 \%$ and at least 1 error pertinent to implantation. Calder $\mathrm{SJ}$ et $\mathrm{al}^{23}$ in their comparative study has shown that after adjusting for confounding factors, such as differences in the level of function before injury between the groups, the degree of return to the pre-injury state was significantly greater $(p=0.04)$ when using the unipolar prosthesis, which is one-quarter of the price of the bipolar. Vander merve ${ }^{24}$ in his study has emphasized the meticulous fitting of the prosthesis for the good result. Acetabular erosion rate of $17.8 \%$ was found in the study of Essoh JB et $\mathrm{al}^{13}$ and $10 \%$ in Jadhav et al.9 We didn't see the acetabular erosion in our series which may be due to the short period of study

\section{Conclusion}

Hemiarthroplasty with Austin Moore Prosthesis is safe and effective method of treatment for displaced fracture neck of femur in elderly. There was early post-operative full weight bearing mobilization with reduction in major complications. The operative duration, post-operative complications are comparable to other similar studies done elsewhere. The end functional results also depend on the associated comorbidities and optimum post op rehabilitation. However, similar study with large sample size and longer follow up will be required to assess the long term results.

So, Austin Moore Hemiarthroplasty gives good functional outcome in fracture neck of femur in elderly patients.

\section{References}

${ }^{1}$ MASSON M, P. M., FLEICHER S. Cochrene Database of systemic reviews. 2004

2 Gullberg B, Johnell O, Kanis J. World-wide Projections for Hip Fracture. Osteoporosis International. 1997;7(5):407-413.

${ }^{3}$ Chapman's orthopaedic surgery, 3rd ed. Philadelphia; Lippincott \& wilkins; 2001, 617-70. 
${ }^{4}$ Krahn TH, Canale ST, Beaty JH, Warner WC, Lourenço P. Long-term follow-up of patients with avascular necrosis after treatment of slipped capital femoral epiphysis. J Pediatr Orthop. 1993 Mar-Apr;13(2):154-8.

5 Terai T, Henmi T, Kanematsu Y, Fujii K, Mishiro T, Sakai T. Clinical Evaluation of Aged Patients Who Underwent Surgery for Femoral Neck Fractures - Comparative Study of Clinical Results According to Age. Journal of Orthopaedic Surgery. 2002;10(1):23-28.

${ }^{6}$ Parker MJ, Khan RJ, Crawford J, Pryor GA. Hemiarthroplasty versus internal fixation for displaced intracapsular hip fractures in the elderly. A randomised trial of 455 patients. J Bone Joint Surg Br,2002; 84: 1150-5.

${ }^{7}$ Hardinge K. The direct lateral approach to hip. J Bone Joint Surg Br. 1982; 64(1):17-9.

${ }^{8}$ Dhar D. Early results of austin moore prosthesis in elderly patients with fracture neck femur. J Orthop, 2007;4(1)e3

9 Jadhav AP, Kulkarni SS, Vaidya SV, Divekar MM, Suralkar SP. Results of Austin Moore replacement. J Postgrad Med, 1996; 42: 33-8.

10 Jensen JS, Holstein P. A long term follow-up of Moore arthroplasty in femoral neck fractures. Acta Orthop Scand, 1975; 46 :764-74.

11 Moore AT. The self-locking metal hip prosthesis. J Bone Joint Surg Am, 1957; 39(A): 811-27.

12 Noor SS, Javed NN. Outcome of Austin Moore Hemiarthroplasty in elderly patients with fracture neck of femur. J of Pakistan Orthopedic Association,2012; 22: 14-19.

${ }^{13}$ Essoh JB, Sie MD, Aka D, Kacou MD, Kodo MD, lambin MD. Austin moore hemiarthroplasty for displaced fracture neck of fractures in patients aged 55years and above. An Ivorian experience. Nigerian journal of trauma and Orthopaedics. 2006;5:18-24.

14 Norrish AR, Rao J, Parker MJ.Prosthesis survivorship and clinical outcome of the Austin Moore hemiarthroplasty: An 8-year mean follow-up of a consecutive series of 500 patients.Injury. 2006 Aug;37(8):734-9.

15 Clayer M, BbrucknerJ. The outcome of Austin-Moore hemiarthroplasty for fracture of the femoral neck. Am J Orthop (Belle Mead NJ). 1997 Oct;26(10):681-4.

16 Singh M, Nagrath AR, Maini PS.Changes in trabecular pattern of the upper end of the femur as an index of osteoporosis. J Bone Joint Surg Am, 1970; 52: 457-67.

17 Anderson Ld, Hamsa Wr, Waring TI.Femoral-Head Prostheses. A Review Of Three Hundred And Fifty-Six Operations And Their Results. J Bone Joint Surg Am. 1964 Jul;46:1049-65.

${ }^{18}$ Kanchanbat B, Stapanavatr W, Meknavin S, Soorapanth C, Sumanasrethakul C, Kanchanasuttirak P.Systematic review and meta-analysis on the rate of postoperative venous 
thromboembolism in orthopaedic surgery in Asian patients without thromboprophylaxis. $\mathrm{Br} \mathrm{J}$ Surg,2011; 98: 1356-64.

${ }^{19}$ Kuokkanen $\mathrm{H}$, Lehtonen J, Korkala O.Austin Moore replacement hemiarthroplasty in femoral neck fractures of the elderly. Ann Chir Gynaecol,1988; 77: 160-3.

${ }^{20}$ Sharif KM, Parker MJ.Austin Moore hemiarthroplasty: technical aspects and their effects on outcome, in patients with fractures of the neck of femur. Injury,2002; 33: 419-22.

${ }^{21}$ Smith DM, Oliver CH, Ryder CT, Stinchfield FE.Complications of Austin Moore arthroplasty. Their incidence and relationship to potential predisposing factors. J Bone Joint Surg Am, 1975;57: 31-3.

${ }^{22}$ Weinrauch P. Intra-operative error during Austin Moore hemiarthroplasty. J Orthop Surg (Hong Kong),2006; 14: 249-52.

${ }^{23}$ Calder SJ, Anderson GH, Jagger C, harper WM, Gregg PJ.Unipolar or bipolar prosthesis for displaced intracapsular hip fracture in octogenarians: a randomised prospective study. J Bone Joint Surg Br, 1996; 78: 391-4.

${ }^{24}$ Vandermerwe DF, Deklerk AJ, Vlok GJ.Results of the use of the Austin Moore prosthesis for the treatment of femur neck fracture at Tygerberg Hospital. A retrospective study]. S Afr Med J, 1990;77: 519-22. 